\title{
EDITORIAL
}

\section{Taboo: crossing the specialty barrier}

\author{
A.K. Simonds* and M.R. Cowie
}

$\Delta$ rguably the greatest therapeutic breakthroughs have resulted from increased medical specialisation, particularly in major disciplines, such as cardiology and respiratory medicine. Generalism now remains the province of primary and community care, and of elderly care teams. However, what works well for research may work against the delivery of these medical advances to the patients most in need. A movement away from the established reductionist approach in medicine may facilitate the delivery of best care for a number of reasons in both cardiology and respiratory medicine, as follows.

1) Huge efforts are currently directed at preventing repeat admissions from exacerbations of heart failure and chronic obstructive pulmonary disease (COPD), facilitating early discharge and managing patients in the community [1-4]. Home support, including telecare, may help both groups. Moreover, a number of telecare schemes now have joint networks serving COPD and heart failure patients [5].

2) Pulmonary and cardiac rehabilitation programmes are crucial and effective components of long-term care plans in chronic cardiac and respiratory patients, yet in many centres rehabilitation programmes have evolved, and are staffed, separately. While there is a need to tailor programmes to the nature of the disease and its severity, courses could easily improve coordination with each other, and share facilities and expertise. Also, the role of joint exercise courses should be examined earlier in the natural history of cardiorespiratory disease.

3) Sleep-disordered breathing (SDB) is increasingly recognised in patients with ischaemic heart disease where obstructive sleep apnoea (OSA) may compound cardiac risk. Chronic heart failure patients also experience SDB. Whereas this was previously considered an end-stage phenomenon, recent work shows SDB occurs in as many as $50 \%$ of patients with mild to moderate heart failure [6], and these patients predominantly have central sleep apnoea (CSA)/Cheyne-Stokes respiration. While the evidence to support continuous positive airway pressure (CPAP) therapy in sleepy heart disease patents with OSA is secure $[7,8]$, controversy reigns over the value of treating CSA $[9,10]$. The identification of heart failure patients

\footnotetext{
*Academic and Clinical Unit of Sleep and Breathing, Royal Brompton Hospital, and ${ }^{*}$ Dept of Cardiology, National Heart and Lung Institute, Imperial College, London, UK.
}

STATEMENT OF INTEREST: A statement of interest for A.K. Simonds and M.R. Cowie can be found a www.erj.ersjournals.com/misc/statements.shtml

CORRESPONDENCE: A.K. Simonds, Academic and Clinical Unit of Sleep and Breathing, Royal Brompton Hospital, London SW3 6NP, UK. Fax: 44 2073518911. E-mail: a.simonds@rbht.nhs.uk with SDB is problematic, as while OSA patients are sleepy, heart failure patients with CSA are not [11]. In many European centres, sleep services fall within the compass of respiratory medicine, so cardiology and respiratory medicine teams must work together to develop sensible, practical strategies for screening sleep studies and applying effective therapy. As a by-product, this cooperative approach will facilitate research trials determining, for example, whether CPAP reduces cardiovascular risk and symptoms in patients with mild to moderate OSA (MOSIAC trial, Oxford Sleep Unit/MRC Clinical Trials Unit, UK; in progress) or whether innovative approaches, such as adaptive servo-ventilation, improve cardiac outcomes in heart failure patients with central SDB $[12,13]$. The cooperative approach stimulated by the Serve-HF trial, led jointly by European cardiac and respiratory investigators, may act as a useful example.

4) End-of-life care issues in heart failure and respiratory failure contain many similar elements [14]. Although therapies may differ, the key focus is on supportive care, shared decision making, symptom control and family support. Palliative care specialists cannot reasonably deal with this substantial patient load on an individual basis, as deaths from cardiac and respiratory disease dwarf those from cancer. The only way forward is for palliative and supportive care expertise to be disseminated to those responsible for patient care. Artificial barriers between cardiology and respiratory teams do not serve these patients well.

5) Breathlessness assessments: as increasing specialism occurs among general practitioners and in hospital practice, the investigations performed often depend on who the patient sees, rather than the most likely diagnosis, pointing to the need for a more broadly based one-stop/rapid access clinics.

6) Finally, and most obviously, many of our patients have coexisting cardiac and respiratory disease. While this aspect may be underestimated by clinical trials, which tend to exclude co-pathology, in the real world of ageing patients sensible management will always embrace all conditions, the interaction between these [15], and the effects of polypharmacy [16]. Readers will undoubtedly point to thriving examples of coworking between respiratory medicine and cardiology teams but across Europe these are patchy and not systematically organised or planned.

What is the greatest barrier to a cross-specialty approach? Probably doctors themselves. Other healthcare professionals often have a more flexible attitude and greater experience with multi-professional and multi-agency teamworking. Resistance to such an approach may be encouraged by the need to choose a specialty early in medical training, and diverging tracks and 
knowledge base as careers progress. Essentially though, there is no reason why we cannot fuse the advantages of specialism in research, where applicable, and the advantages of integration for the delivery of care. This approach does not deny that excellent, innovative academic research can be generated by the cross pollination of ideas, or that research into the processes and delivery of care is important. Indeed the latter is crying out for a robust evidence base [17, 18], rather than a headlong rush for new initiatives $[19,20]$. For example, cost savings from hospital-at-home schemes will only accrue if acute care costs are relatively high, and may not translate easily across healthcare systems or geographically [19].

In most European countries there is a stated imperative to reduce hospital admissions and devolve care to the community. Numerous factors drive this aim, including cost and patient preference. Some healthcare team members see this move as a threat to current professional practice, and an opportunity for governments to fragment care. Economically, there is no doubt that changes in the delivery of care are required, and from the perspective of our patients it is important that these initiatives combine the best of cardiology and respiratory practice, rather than an homogenised, lowest common denominator approach. For this to be achieved, an integrated approach between secondary and primary care is likely to produce the best outcomes. Our thesis is that this vertical integration from hospital to community care should be accompanied by lateral integration between specialties.

So, let's break down the barriers. There is much to be gained, and little to be lost.

\section{REFERENCES}

1 Phillips CO, Wright SM, Kern DE, Singa RM, Shepperd S, Rubin HR. Comprehensive discharge planning with postdischarge support for older patients with congestive heart failure. A meta-analysis. JAMA 2004; 291: 1358-1367.

2 Stewart S, Horowitz JD. Home-based intervention in congestive cardiac failure: long term implications on readmission and survival. Circulation 2002; 105: 2810-2812.

3 Casas A, Troosters T, Garcia-Aymerich JRJ, et al. Integrated care prevents hospitalisations for exacerbations in COPD patients. Eur Respir J 2006; 28: 123-130.

4 Ram FSF, Wedzicha JA, Wright J, Greenstone M. Hospital at home for patients with acute exacerbations of chronic obstructive pulmonary disease: systematic review of evidence. BMJ 2004; 329: 315-318.

5 Vitacca M, Scalvini S, Spanevello A, Balbi B. Telemedicine and home care: controversies and opportunities. Breathe 2006; 3: 148-158.

6 Vazir A, Hastings PC, Dayer M, et al. A high prevalence of sleep disordered breathing in men with mild symptomatic chronic heart failure due to left ventricular systolic dysfunction. Eur J Heart Fail 2006; 9: 243-250.

7 Takasaki Y, Orr D, Popkin J, Rutherford R, Liu P, Bradley TD. Effect of nasal continuous positive airway pressure on sleep apnea in congestive heart failure. Am Rev Respir Dis 1989; 140: 1578-1584.

8 Mansfield DR, Gollogly NC, Kaye DM, Richardson M, Bergin P, Naughton MT. Controlled trial of continuous positive airway pressure in obstructive sleep apnoea and heart failure. Am J Respir Crit Care Med 2004; 169: 361-366.

9 Bradley TD, Logan AG, Kimoff J, et al. Continuous positive airway pressure for central sleep apnea and heart failure. N Engl J Med 2005; 353: 2025-2033.

10 Artzt M, Floras JS, Logan AG, et al. Suppression of central sleep apnea by continuous positive pressure airway pressure and transplant-free survival in heart failure. A post hoc analysis of the Canadian Continuous Positive Airway Pressure for Patients with Central Sleep Apnea and Heart Failure Trial (CANPAP). Circulation 2007; 115: 3173-3180.

11 Hastings PC, Vazir A, O’Driscoll DM, Morrell MJ, Simonds AK. Symptom burden of sleep-disordered breathing in mild-to-moderate congestive heart failure patients. Eur Respir J 2006; 27: 748-755.

12 Teschler H, Dohring J, Wang YM, Berthon-Jones $\mathrm{M}$. Adaptive pressure support servo-ventilation: a novel treatment for Cheyne-Stokes respiration in heart failure and central sleep apnea. Am J Respir Crit Care Med 2001; 164: 614-619.

13 Philippe C, Stoica-Herman M, Druout X, et al. Compliance with and effectiveness of adaptive servoventilation versus continuous positive airway pressure in the treatment of Cheyne-Stokes respiration in heart failure over a six month period. Heart 2006; 92: 337-342.

14 Selecky PA, Eliasson CAH, Hall RI, Schneider RF, Varkey B, McCafree DR. Palliative and end-of-life care for patients with cardiopulmonary diseases. American College of Chest Physicians Position Statement. Chest 2005; 128: 3599-3610.

15 Watz H, Waschki B, Boehme C, Claussen M, Meyer T, Magnussen H. Extrapulmonary effects of chronic obstructive pulmonary disease on physical activity. A cross sectional study. Am J Respir Crit Care Med 2008; 177: 743-751.

16 Stevenson J, Abernethy AP, Miller C, Currow DC. Managing comorbidities in patients at the end of life. BMJ 2004; 329: 909-912.

17 Wagner EH. Deconstructing heart failure disease management. Ann Intern Med 2004; 141: 644-646.

18 British Thoracic Society Guideline Development Group, Intermediate care - hospital-at-home in chronic obstructive pulmonary disease: British Thoracic Society guideline. Thorax 2007; 62: 200-210.

19 Shepperd S. Hospital at home: the evidence is not compelling. Ann Intern Med 2005; 143: 840-841.

20 Coleman EA, Berenson RA. Lost in transition: challenges and opportunities for improving the quality of transitional care. Ann Intern Med 2004; 140: 533-536. 